\title{
Health Status Examination of Sumatran Elephant (Elephas maximus sumatranus) Using Ultrasonography, Cortisol Analysis and Parasite Identification in Aek Nauli Elephant Conservation Camp (ANECC) and Tangkahan Conservation Response Unit (CRU), North Sumatra
}

\author{
Juli Melia ${ }^{1}$, Amalia Sutriana ${ }^{2 *}$, Muhammad Hanafiah $^{3}$, Muhammad Wahyu $^{4}$, Anhar Lubis $^{4}$, Aulia Fakhrurrozi $^{4}$, \\ Teuku A. Maulana ${ }^{4}$, and Masyitah N. Sari ${ }^{4}$ \\ ${ }^{1}$ Reproduction Laboratory, Faculty of Veterinary Medicine, Syiah Kuala University, Banda Aceh, Indonesia \\ ${ }^{2}$ Pharmacology Laboratory, Faculty of Veterinary Medicine, Syiah Kuala University, Banda Aceh, Indonesia \\ ${ }^{3}$ Parasitology Laboratory, Faculty of Veterinary Medicine, Syiah Kuala University, Banda Aceh, Indonesia \\ ${ }^{4}$ Veterinary Society Consortium for Sumatran Wildlife Conservation, Indonesia
}

\begin{abstract}
In North Sumatera, captive Sumatran elephants are maintained in several conservation units, 2 of them were Aek Nauli Elephant Conservation Camp (ANECC) and Tangkahan Conservation Response Unit (CRU). Although elephant conservation sites have implemented a management plan to address elephant health and welfare issues, Sumatran elephants in captivity are still susceptible to some of the health issues such as breeding problems, stress, and poor health. Therefore, the health examination is necessary to be conducted regularly as an effort to save the Sumatran elephant which has been categorized as one of the critically endangered animals. This study was carried out in Aek Nauli and Tangkahan which covered the assessment of elephant reproduction status using ultrasonography, cortisol analysis using ELISA, and parasite identification using sedimentation, floatation and Parfit and Banks methods. The ultrasonography examination was carried out on each conservation site, while the collected blood and feces were transferred to Veterinary Medicine Faculty Universitas Syiah Kuala for cortisol and parasite analysis, respectively. The data on reproductive status, cortisol level, and gastrointestinal parasite were analyzed descriptively. The sonography result showed that 3 Sumatran elephants in ANECC had uterine cysts, while one pregnant elephant and two elephants with involution uteri were recorded in CRU Tangkahan. Worm eggs from genus trematode and nematode were found during feces examination in ANECC, but the only nematode was observed in Tangkahan. Elephant maintained in Tangkahan had a higher cortisol level $(82.11 \pm 61.49 \mathrm{ng} / \mathrm{ml})$ compared to those maintained in ANECC $(16.87 \pm 3.88 \mathrm{ng} / \mathrm{ml})$. As a conclusion, the reproduction status, cortisol level, and parasite gastrointestinal observed in Sumatran elephant maintained in 2 conservation sites (ANECC and CRU Tangkahan) were different, probably due to different stress factor and management implemented on.
\end{abstract}

Keywords: ANECC, health status, Sumatran elephant, CRU Tangkahan.

\section{Introduction}

Sumatran elephants (Elephas maximus sumatranus) are included in the sub-species of Asian elephants that only exist on the island of Sumatra $[1,2,3]$. Sumatran elephant is one of the endangered fauna in Indonesia. One effort in protecting elephants is conservation. Conservation is an effort to conserve animals that are carried out outside their habitat (ex-situ). This conservation effort is carried out in conservation institutions in the form of governmental and non-governmental institutions, which is designated with main and secondary functions for the public interest.

The maintenance of elephants in conservation areas raises controversy, especially about elephant welfare. Issues of elephant welfare in conservation areas are related to reproduction, health, obesity, stereotypic behavior, and lack of opportunities for normal creativity [4]. A poor conservation management system will result in stress on the elephant which will ultimately harm the elephant's reproductive system and overall health status in the conservation area.

Increased cortisol hormone concentration is one indicator of stress in animals [5, 6,7]. According to Borell [8], transportation and treatment before slaughter can cause stress on animals and have detrimental effects on the animal's health and well-being. Measurement of cortisol hormone concentration is the most commonly used method for evaluating stress from animal handling

*Corresponding author: amalia_sutriana@unsyiah.ac.id 
$[9,10,11,12]$. Another form of threat that can disrupt the health of elephants in conservation areas is the disease from parasitic infestations such as nematodes, trematodes or cestodes worms. Parasites such as gastrointestinal nematodes are abundant among animals and cause subclinical effects such as poor body condition and growth [13].

Therefore, this study aimed to detect the level of stress on elephants affected by patterns of maintenance and health screening through the identification of worms in elephants that are sheltered in 2 conservation areas in North Sumatra. Ultrasound examination is necessary to observe the relationship between health cases in elephants with the reproductive system.

\section{Materials and Methods}

This study uses tamed Sumatran elephants in two conservation areas, namely Aek Nauli Elephant Conservation Camp (ANECC) and Tangkahan CRU, North Sumatra. Research activities include: 1) Reproductive organ screening using ultrasonography, 2) Cortisol hormone analysis, 3) parasite examination.

\subsection{Screening of Reproductive Organs Using Ultrasonography (USG)}

Sonographic examination of the female elephant's reproductive tract includes the uterus (cervix, body, and horn) and ovaries. Stool removal and rectal exploration were conducted before sonography. Subsequently, a trans-rectal probe was inserted along the female elephant reproduction tract. Scanning was performed on all visible uterine and ovarian images. The results were recorded in the form of a sonogram.

\subsection{Cortisol Hormone Analysis}

$10 \mathrm{~mL}$ of blood samples were collected in the morning and then centrifuged at $200 \mathrm{rpm}$. Plasma obtained was then placed into an Eppendorf cryotube and stored in a freezer at -20C until the assay process was carried out. The cortisol hormone level was measured using a human cortisol Enzyme-Linked Immunosorbent Assay (ELISA) kit ( Cat. No. EIA-1887, DRG Instruments GmbH, Germany). This assay has been validated for animals [21].

\subsection{Internal Parasite Examination}

A stool examination was performed to determine the presence of worm eggs or infective larvae. This examination is also intended to diagnose the level of internal parasitic worm infections in the animals. Stool examination can be done with qualitative and quantitative methods.

\subsubsection{Native Method}

Elephant feces were placed on a clean object-glass using a dropper and then dropping 1-2 drops of water. Using the dropper, we flattened or dissolved it, then covered it with a glass cover and examine it under a microscope with a magnification of 10x.

\subsubsection{Sedimentation Method}

The stool was placed into a centrifuge tube and water is added to $3 / 4$ tube or $\pm 13 \mathrm{ml}$, then closed and stirred until homogeneous. The sample was then placed into a centrifuge and centrifuged at a speed of $1500 \mathrm{rpm}$ for \pm 5 minutes. The supernatant was removed by pouring the test tube quickly and leaving a little amount of supernatant. From the remaining supernatant, 1 drop was taken and placed on the glass object then covered with a glass cover before being examined under a microscope with a magnification of $10 x$.

\subsubsection{Floating Method}

The saturated salt solution was added to the stool deposit in the centrifuge until it appeared convex. Then covered with a glass cover and left for 5 minutes. After 5 minutes the glass cover is taken and stored in the glass object. Observations were made under a microscope with a magnification of $10 \mathrm{x}$.

\subsection{Data analysis}

Data from the sonographic examination of the reproductive tract, cortisol hormone cod, and internal parasitic examination were analyzed descriptively and presented in the form of images and tables.

\section{Results and Discussion}

\subsection{Elephant Reproductive Health}

\subsubsection{The elephant in Aek Nauli, North Sumatra}

The sonographic examination result of the elephant Siti's reproductive tract showed the presence of cysts inside the uterus (Figure 1). Although there were many cysts, the size of the cysts was small. The same finding was found from elephant Vini whose uterus contained cystic growth with very small diameters (Figure 2).

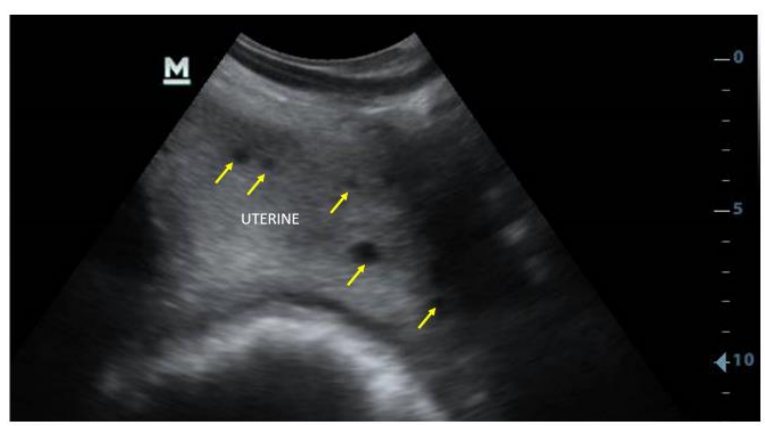

Figure 1. Cysts in the uterus of elephant Siti

There was no connective tissue growth in the uterine endometrial mucosa in both elephant Siti and Vini, indicating that their uterus was still in good condition despite the presence of cysts. 

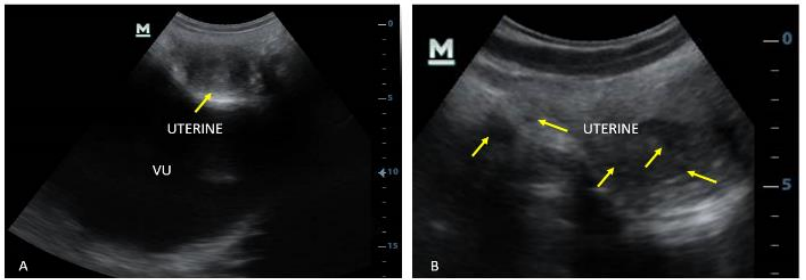

Figure 2. Condition of elephant Vini's uterus. A. Uterine sonography; B. Longitudinal section of uterus, arrow=small cysts (VU: bladder).

Examination of the reproductive tract of elephant Esther showed that the uterus was slightly dirty, but no connective tissue growth was found in the uterine mucosa. Growth of follicles in the elephant Esther's ovary was very few. Only one dominant follicle was found with a diameter of $2.07 \mathrm{~cm}$ (Figure 3). Hodges [14] stated that pre-ovulatory follicles in African elephants only reach a maximum diameter of $0.5-1.0 \mathrm{~cm}$, while according to Hermes [15] the diameter is around $21.0 \mathrm{~mm}$ in African elephants and 20.2 in Asian elephants [16].
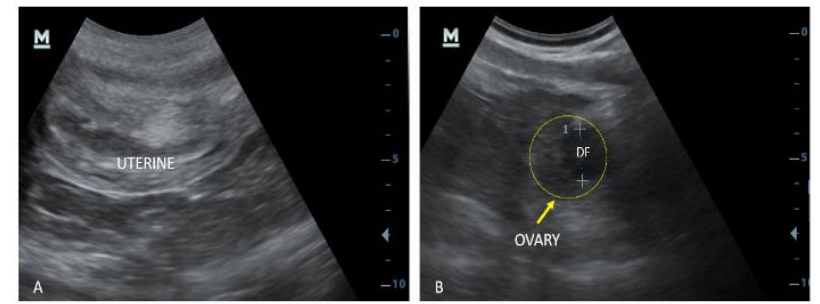

Figure 3. Uterus and ovarium of elephant Esther. A. Uterus condition is relatively normal albeit slightly dirty, with no connective tissue growth; B. Dominant follicles in ovarium with a diameter of $2.07 \mathrm{~cm}(\mathrm{DF})$.

Based on the results of the ultrasound examination of the reproductive organs in the three elephants, it can be seen that there is an indication of the infertility problem. This is marked by the presence of multiple tiny cysts and minimal follicle growth in the ovaries. However, the lack of fertility can be corrected because there was no inflammation in the uterus. The elephants should be given better nutritional intake and vitamin $\mathrm{E}$ to improve fertility.

\subsubsection{Elephants in CRU Tangkahan, North Sumatra}

The examination on elephant Ardana reproduction examination showed that the elephant was pregnant. This is seen by the detection of fetal body parts through sonography (Figure 4). Meanwhile, sonography of elephant Olive (Figure 5) and Yuni (Figure 6) showed an enlarged uterus with a clean lumen. It is estimated that the two elephants were still in the stage of uterine involution and the lactation period. This is supported by the presence of baby elephants who were still breastfeeding.
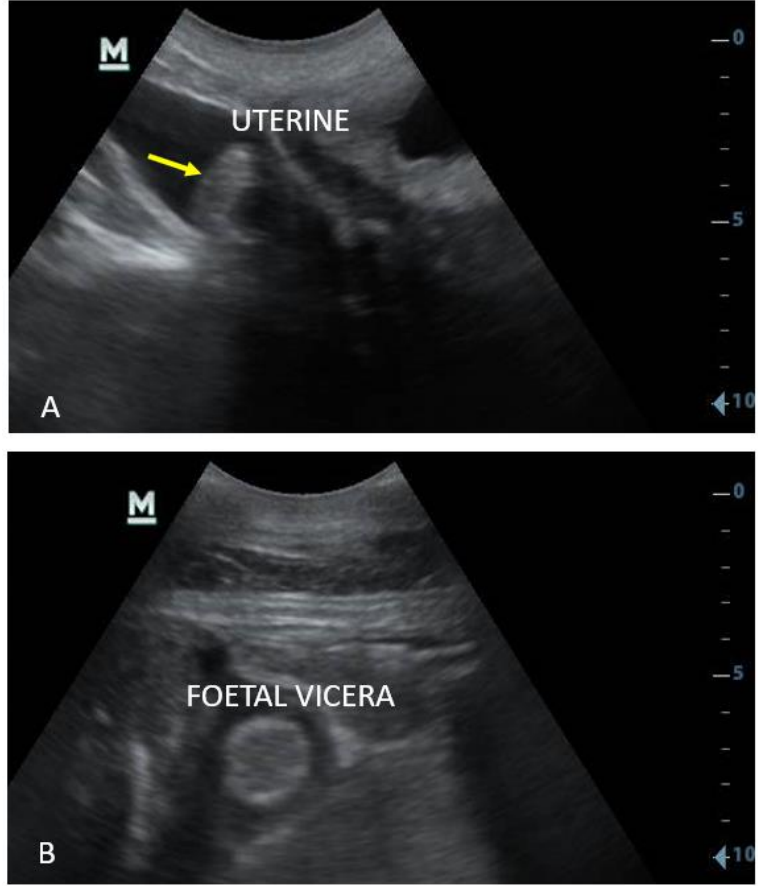

Figure 4. Sonographic image of pregnancy in elephant Ardana. A. Uterus containing fetus; B. fetus' visceral organ, arrow=fetal trunk.

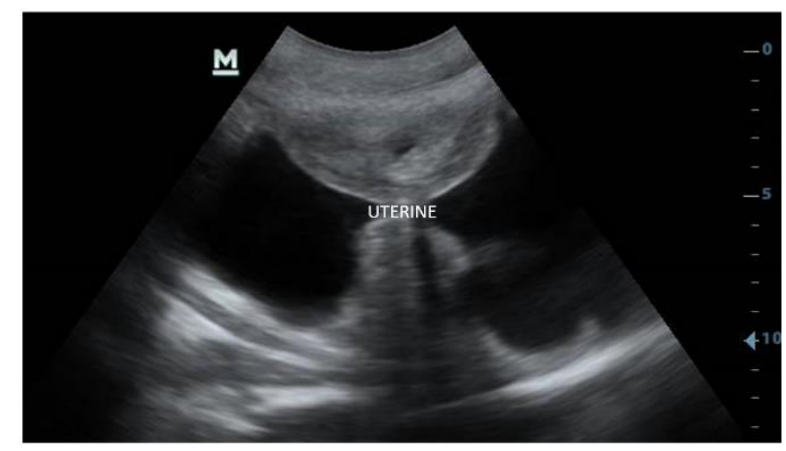

Figure 5. Uterine involution in elephant Olive

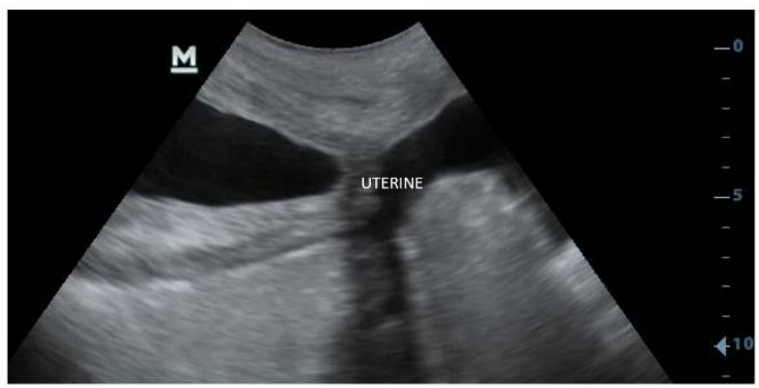

Figure 6. Uterine involution in elephant Yuni with a uterus that was still larger than normal

The result of an examination of elephant Sari showed a uterus in good condition without inflammation in the uterine endometrial mucosa and there was clear fluid (anechoic) in the uterine lumen. In the ovary, follicles were found to grow in small amounts (Figure 7). Most likely, elephant Sari was in the follicular phase. If nutritional intake is sufficient, the elephant will enter the 
pre-estrous stage followed by estrous phase, therefore the availability of sufficient nutritional intake and vitamins was urgently needed.
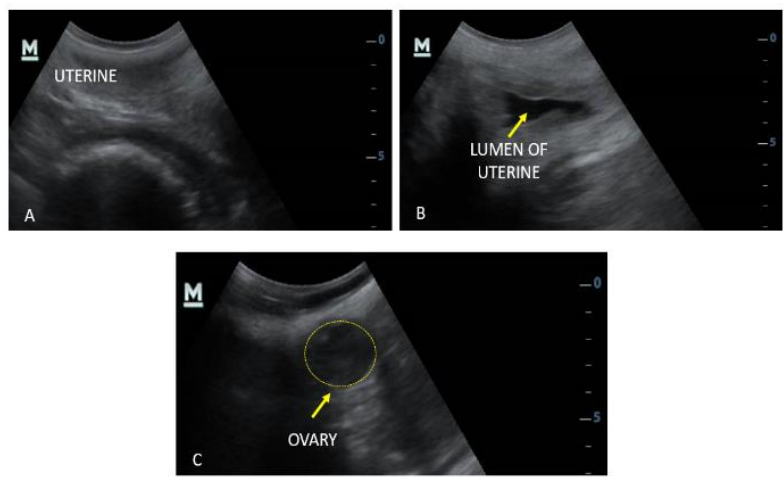

Figure 7. Sonography of reproduction tract of elephant Sari. A. Uterus normal; B. Uterine lumen filled with clear fluid; C. Ovarium with several follicular growths.

\subsection{Cortisol Hormone Analysis}

Blood cortisol hormone examination was carried out on 3 female elephants (Esther, Pini, Siti) in Aek Nauli and 7 elephants in Tangkahan CRU. The elephants which were examined at Tangkahan CRU consisted of 1 male elephant (Theo), 4 female elephants (Agustina, Olip, Yuni, Sari), 1 pregnant female elephant (Ardhana), and 1 calf (European). The cortisol hormone inspection data from each of the elephants mentioned above are presented in Table 1 and Table 2.

Table 1. Cortisol levels (ng/ml) in Sumatran elephants (Elephas maximus sumatranus) in Aek Nauli Captivity

\begin{tabular}{ll}
\hline Name of the elephant & Cortisol Level \\
\hline Ester & 15.95 \\
Pini & 21.64 \\
Siti & 12.91 \\
\hline Average \pm SD & $16.87 \pm 3.88$
\end{tabular}

Table 2. Cortisol levels (ng/ml) in Sumatran elephants (Elephas maximus sumatranus) at CRU Tangkahan

\begin{tabular}{ll}
\hline Name of the elephant & Cortisol Level \\
\hline Agustina & 72.71 \\
Olip & 83.55 \\
Sari & 82.77 \\
Ardana & 13.32 \\
Yuni & 208.86 \\
Eropa & 15.16 \\
Teo & 76.09 \\
\hline Average \pm SD & $82.11 \pm 61.49$
\end{tabular}

Based on the results of hormone testing using the EIA technique, it was found that the range of the cortisol hormone among the three elephants in Aek Nauli was $12.91-21.64 \mathrm{ng} / \mathrm{ml}$ with an average of $16.87 \pm 3.88 \mathrm{ng} / \mathrm{ml}$. The range of cortisol levels among seven elephants in CRU Tangkahan was 13.32-208.86 ng/ml with an average of $82.11 \pm 61.49 \mathrm{ng} / \mathrm{ml}$. Cortisol hormone levels in elephant Ardana was less than other elephants (13.32 $\mathrm{ng} / \mathrm{ml}$ ). The low cortisol level in Ardana's elephant was caused by its pregnancy. During pregnancy, the cortisol level must be low until near parturition. High cortisol levels during the pregnancy phase could cause induction of preterm birth or abortion. Elephant Yuni had very high cortisol levels $(208.86 \mathrm{ng} / \mathrm{ml})$ compared to other elephants in CRU Tangkahan. This might be due to the difficulty in taking a blood sample from elephant Yuni. During blood sampling, Yuni appeared more agitated. Yuni was still breastfeeding; separation from the child during blood sampling might have caused anxiety.

Cortisol level is usually associated with stress levels in an individual. According to Moberg [17], stress response involves the release of glucocorticoids, such as cortisol, from the adrenal glands, and changes in cortisol concentration are generally used as physiological indicators of stress. EIA examination result showed that the baseline cortisol level among elephants in CRU was much higher than in Aek Nauli $(82.11 \pm 61.49 \mathrm{ng} / \mathrm{ml}$ vs $16.87 \pm 3.88 \mathrm{ng} / \mathrm{ml}$ ). This difference might be caused by the popularity of CRU Tangkahan. Possible sources of stress on elephants in captivity include artificial lighting, unpleasant sound exposure, strong odors, limited movement, and proximity to humans $[18,19]$, separation from the herd, feeding management [20].

\subsection{Parasite Identification}

From the result of parasitic examinations carried out at Aek Nauli, parasitic eggs from the phylum Nematode, Trematode, and the genus Eimeria spp. (Figure 8) were found. Nematode eggs have morphological similarities [22], making it difficult to identify nematodes up to the genus. Besides, due to the feces was stored in $10 \%$ formalin, nematode eggs in elephant feces cannot be cultured to the next stage (larvae 3) [23], therefore identification is not possible to the species stage.
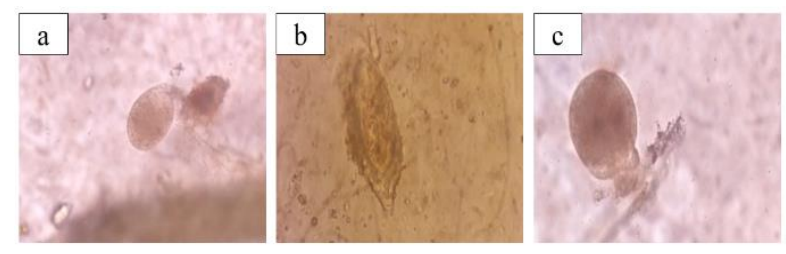

Figure 8. Parasite eggs under the microscope with a magnification of $10 \times 40$, in elephant feces from Aek Nauli (a. Nematode, b. Tematode, c Eimeria spp.)

Out of the 4 elephants examined, 2 were positive for nematode infestation, 2 were infested with trematodes, 1 was infested with Eimeria spp., while the other elephant was free from parasites (Table 3). The overall percentage of parasitic infestations in elephants in Aek Nauli can be seen in Table 4.

From the results of the parasitic examination on 5 elephants in the CRU Tangkahan (Ardana, Olip, Sari, Yuni, and Theo), 1 sample (Ardana) was positively infested with nematode (Figure 9, Table 5). 
Table 3. Result of examination for eggs and larvae of nematodes in Sumatra elephants (Elephas maximus sumatranus) in Aek Nauli

\begin{tabular}{lcccc}
\hline \multirow{2}{*}{$\begin{array}{l}\text { Name } \\
\text { Elephant }\end{array}$} & \multirow{2}{*}{\begin{tabular}{l}
\multicolumn{4}{l}{ Parasite Egg Examination Result } \\
\cline { 3 - 4 }
\end{tabular}} & $\mathrm{e}$ & $\mathrm{e}$ & Eimeria spp. \\
\hline Lubing & + & - & + \\
Ester & - & + & - \\
Vini & - & - & - \\
Siti & + & - & + \\
\hline
\end{tabular}

Table 4. Percentage of parasitic infestations in Sumatra elephants (Elephas maximus sumatranus) in Aek Nauli

\begin{tabular}{lllccccr}
\hline Location & Nematode & Trematode & $\begin{array}{c}\text { Eimeria } \\
\text { spp. }\end{array}$ & $(-)$ & $(+)$ & Total & \\
\hline Aek & 2 & 2 & 1 & 1 & 3 & 4 & 2. \\
Nauli & & & 1 & 1 & 3 & & \\
Total & $2(50 \%)$ & $2(50 \%)$ & $(25 \%)$ & $(25 \%)$ & $(75 \%)$ & $100 \%$ & 3. \\
\hline
\end{tabular}

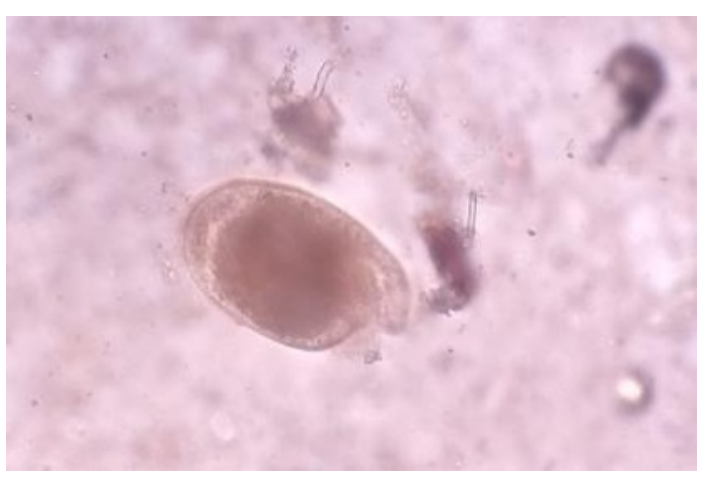

Figure 9. Nematode egg inside feces from an elephant at CRU Tangkahan (microscopic examination with the magnification of $10 \times 40)$.

Table 5. Parasite identification in Sumateran elephant (Elephas maximus sumatranus) at CRU Tangkahan

\begin{tabular}{lllllll}
\hline Location & $\begin{array}{l}\text { Nema } \\
\text { tode }\end{array}$ & $\begin{array}{l}\text { Trema } \\
\text { tode }\end{array}$ & $\begin{array}{l}\text { Eim } \\
\text { eria }\end{array}$ & $(-)$ & $(+)$ & $\begin{array}{l}\text { Tot } \\
\text { al }\end{array}$ \\
\hline $\begin{array}{l}\text { CRU } \\
\text { Tangkaha }\end{array}$ & 1 & 0 & 0 & 4 & 1 & 5 \\
$\mathrm{n}$ & & & & & & \\
Total & $\begin{array}{l}1(20 \\
\%)\end{array}$ & 0 & 0 & $\begin{array}{l}4 \\
(80\end{array}$ & $\begin{array}{l}1 \\
(20\end{array}$ & 10 \\
& & & & $\%)$ & $0 \%$ \\
\hline
\end{tabular}

Based on anti-helminthic drug administration data to elephants at Aek Nauli and CRU Tangkahan, it was known that the last anti-helminthic administration was conducted in October 2017, while the fecal collection was carried out in September 2018. Factors that could affect the reappearance of worm eggs after anti-helminthic administration are long interval between anti-helminthic drug administration, population density, environment, temperature, and humidity. According to Wilson and Carpenter [24], specifically for endoparasites, worm eggs can appear due to poor sanitation and maintenance and can also be influenced by food hygiene or infection from other infested animals (positive for endoparasites). The habit of elephants at the time of defecation at any place might also aid the return of the parasitic infestation.

\section{Conclusion}

The reproduction status, cortisol level, and parasite gastrointestinal observed in Sumatran elephant maintained in 2 conservation sites (ANECC and CRU Tangkahan) were different, probably due to different stress factors and management implemented on each site.

\section{References}

1. Seidensticker, J: Managing Elephant Depredation in Agricultural and Forestry Projects. The World Bank. Washington D.C., USA. 1984.

Fowler ME, Mikota SK : Biology, Medicine, and Surgery of Elephants. Blackwell. Iowa. 2006.

3. Azmi W Gunaryadi D : Current status of Asian elephant in India. Gajah. 2011; 35:47-54.

4. Clubb R, Mason G:. Captivity effect on wide-ranging carnivores. Nature. 2003; 425:473-474.

5. Fazio E, Ferlazzo A: Evaluation of stress during transport. Vet. Res. Comm. 2003; 27 (sup 1): 519-524.

6. Bayazit V: Gholib. Aust. J. Basic Appl. Sci. 2009; 3:1022-1031.

7. Allwin B, Jayathangaraj MG, Kalaignan PA : Faecal cortisol a non invasive biomarker for stress assessment in wild animals, confounding factors, estimation, quantification, and interpretation. Int. J. Adv. Res. Biol. Sci. 2015; 2(4): 239-251

8. Von Borell EH : The biology of stressand its application to livestock housing and transportation assessment. $J$. Anim. Sci. 2001; 79 (suppl_E):E260-E267.

9. Grandin $\mathrm{T}$ : Farm animal welfare during handling, transport, and slaughter. JAVMA. 1994; 204: 372-377.

10. Kannan G, Kouakou B, Terrill TH, et al. :Endocrine, blood metabolite and meat quality changes in goats as influenced by short-term, preslaughter stress. J. Anim. Sci. 2003; 81:1499-1507.

11. Odore R, D' Angelo A, Badino, $\mathrm{P}$, et al.: Roads transportation affects blood hormone levels and lymphocyte glucocorticoid and $\boldsymbol{\beta}$-adrenergic receptor concentrations in calves. The Vet. J. 2004; 168:297-303.

12. Micera E, Albrizio M, Surdo NC, et al. : Stress-related hormones in horses before and after stunning by captive bolt gun. Meat Sci. 2010; 84: 634-637.

13. Coyne MJ, Smith G: Trichostrongylid parasites of Domestic Ruminant. Parasitic and Infectious Diseases Epidemiology and Ecology. Academic Press, San Diego, CA. 1994.

14. Hodges JK :Endocrinology of the ovarian cycle and pregnancy in the Asian (Elephas maximus) and African (Loxodonta africana) elephant. Anim. Reprod. Sci. 1998; 53, 3-18.

15. Hermes R, Olson D, Goeritz F, et al. : Ultrasonography of the sexual cycle in female African elephants (Loxodonta africana). Zoo Biology.2000; 19: 369-382.

16. Lueders I, Niemuller C, Gray C, et al. : Luteogenesis during the estrous cycle in Asian elephants (Elephas maximus). Reproduction.2010; 140: 777-786. 
17. Moberg G : Influence of stress on reproduction: measure of well-being. In: Moberg GP, editor. Animal stress. Bethesda, MD: American Physiological Society, 1985; p 245-67.

18. Morgan KN, Tromborg CT: Sources of stress in captivity. Appl. Anim. Behav. Sci. 2007; 102: 262-302.

19. Varma S, Sujata SR, Sarma KK, et al.: Captive Elephants in Zoos. 1st edn. Comparison Unlimited plus Action \& Asian Nature Conservation Foundation, Bangalor. 2008.

20. Nishanth B, Srinivasan SR, Jayathangaraj MG,et al. :Fecal cortisol levels in elephants of Tamilnadu State. Indian Vet. J. 2013; 90(2): 42-44.

21. Gholib G, Wahyuni S, Akmal M, et al. : The validation of a commercial enzyme-linked immunosorbent assay and the effect of freeze-thaw cycles of serum on the stability of cortisol and testosterone concentrations in Aceh cattle [version 1; peer review: 1 approved, 1 approved with reservations]. F1000Research 2019, 8:1220.
22. Thienphont H, Mark RL, Rodgers AR: Diagnosing Helminthiasis by Coprological Examination. Jansen Research Foundation, Beerse, Belgium.1979.

23. Indre DGH, Darabus I, Oprescu S, et al. Morphometrical studies on some eggs of gastrointestinal nematodes from sheep. Luc. Stint. Med. Vet, 62(1): 30-35.

24. Wilson SC, Carpenter JW : Endoparasitic disease of reptile. J.f exot. pet med. 1996; 5(2): 64-67. 